
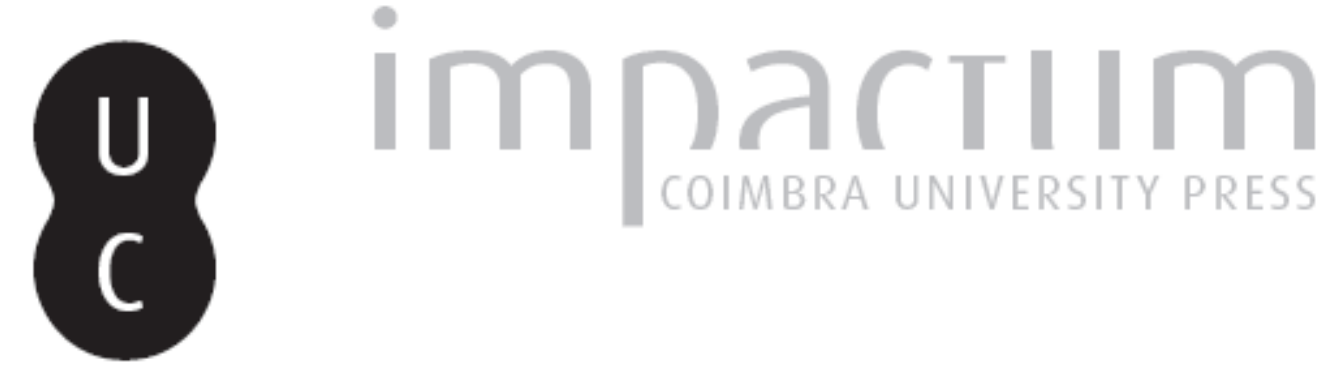

\title{
[Recensão a] PELLEGRINO, B. (dir.) - Ordini religiosi, santi e culti tra Europa, Mediterraneo e Nuovo Mondo (secoli XV-XVII)
}

\author{
Autor(es): $\quad$ Nestola, Paola
}

Publicado por: Centro de História da Sociedade e da Cultura

URL

persistente:

URI:http://hdl.handle.net/10316.2/39540

DOI:

DOI:http://dx.doi.org/10.14195/1645-2259_10-2_14

Accessed : $\quad$ 26-Apr-2023 11:30:30

A navegação consulta e descarregamento dos títulos inseridos nas Bibliotecas Digitais UC Digitalis, UC Pombalina e UC Impactum, pressupõem a aceitação plena e sem reservas dos Termos e Condições de Uso destas Bibliotecas Digitais, disponíveis em https://digitalis.uc.pt/pt-pt/termos.

Conforme exposto nos referidos Termos e Condições de Uso, o descarregamento de títulos de acesso restrito requer uma licença válida de autorização devendo o utilizador aceder ao(s) documento(s) a partir de um endereço de IP da instituição detentora da supramencionada licença.

Ao utilizador é apenas permitido o descarregamento para uso pessoal, pelo que o emprego do(s) título(s) descarregado(s) para outro fim, designadamente comercial, carece de autorização do respetivo autor ou editor da obra.

Na medida em que todas as obras da UC Digitalis se encontram protegidas pelo Código do Direito de Autor e Direitos Conexos e demais legislação aplicável, toda a cópia, parcial ou total, deste documento, nos casos em que é legalmente admitida, deverá conter ou fazer-se acompanhar por este aviso.

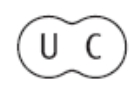




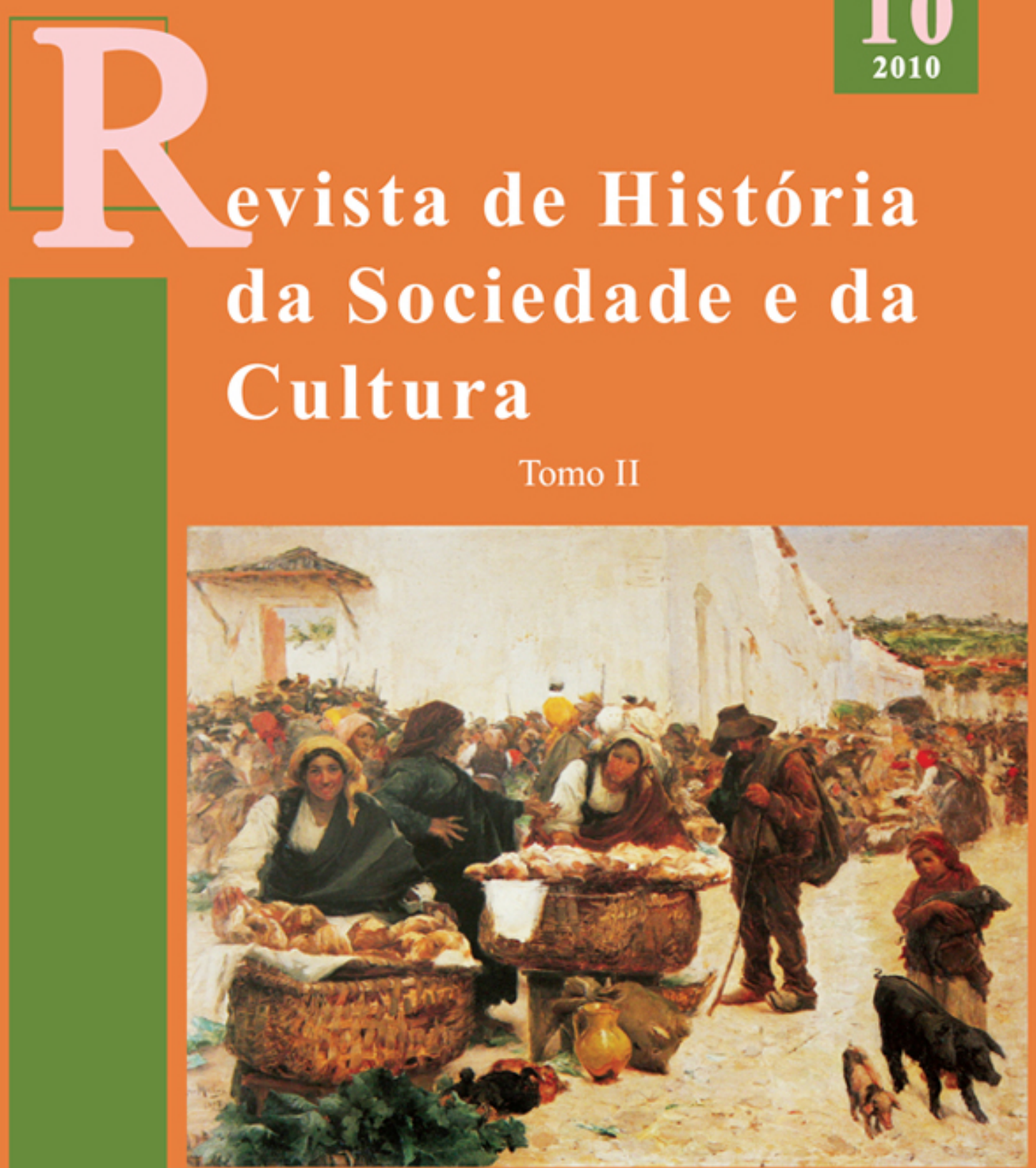

Centro de História da Sociedade e da Cultura Universidade de Coimbra

Coimbra 
essa palavra fosse o resultado de uma "teatralidade obrigatória" que exigia comportamentos apropriados, preparados pela "arte dos consoladores da morte dos condenados". Mesmo que as "frases do protagonista lhe fossem sopradas previamente" (p. 400). Pois, por paradoxal que isso possa parecer aos olhos da cultura sobre a morte hoje dominante nas sociedades ocidentais, ao morrer assim, Lucia redimia-se. Morria para se salvar e purificar a comunidade, tal como sucedera com a morte do seu Cristo. Lucia "dava de novo a alma", tal como no princípio da vida a dera pelo baptismo (p. 401). E assim se fechava um ciclo aproveitado pelo autor, na morte/no fim, para voltar ao princípio da história, para voltar ao princípio do livro e para colocar o leitor perante a mais axial de todas as questões: dar a alma. Um dos livros de História que até hoje mais me fascinou e com o qual aprendi tanto da vida. É que também eu, de novo neste livro, fui um dos estudantes de Adriano Prosperi.

\section{José Pedro Paiva}

Universidade de Coimbra e Centro de História da Sociedade e da Cultura da UC lejpaiva@fl.uc.pt

\section{PELLEGRINO, B. (dir.) - Ordini religiosi, santi e culti tra Europa, Mediterraneo e Nuovo Mondo (secoli XV-XVII). Galatina (LE): Congedo, 2009, 2 vols., 786 p.}

Qual foi o papel das ordens religiosas na promoção dos santos e das devoções entre o Velho e Novo Mundo? É possível analisar comparativamente a contribuição da hagiografia no processo de construção das identidades sociais, políticas e culturais entre o medievo e a modernidade? Quem foram os intermediários privilegiados para responder espiritual e materialmente aos desafios colocados pela repentina irrupção de uma parte ignota e numerosa da humanidade, que durante séculos vivera para além das fronteiras conhecidas da Igreja? Quais eram as estratégias e práticas adequadas para conquistar espiritualmente indivíduos e comunidades tão diferentes entre si nos planos geográfico, cultural, religioso e até no plano jurídico? E quais foram as linguagens político-culturais que se propagaram da Europa mediterrânica até 
ao Atlântico e ao Pacífico transformando-se, hibridizando-se e inovando-se em contacto com as novas terras de missões, marcando de modo inconfundível as novas fronteiras da fé? Eis cinco perguntas chave para introduzir as actas do V congresso internacional AISSCA (Associazione Italiana per lo Studio dei Santi, dei Culti e dell'Agiografia), realizado em Lecce, entre 3 e 6 de Maio de 2003, e que deu origem ao livro que aqui se apresenta, composto por 30 intervenções de especialistas de distintas nacionalidades, além das introduções de Bruno Pellegrino (presidente da "Associazione per la storia sociale del Mezzogiorno e dell' area mediterranea"), de Sofia Boesch Gajano (presidente da AISSCA), de um Prefacio de Gabriella Zarri e um Posfácio de Raimondo Michetti.

A ideia básica para a S. Boesch Gajano foi investigar a santidade interna das ordens religiosas, as experiências religiosas dos santos fundadores e as persistências e inovações dos santos antigos, em função da construção das diversas identidades espirituais e institucionais. Na obra, composta por cinco grandes percursos temáticos e espaciais, uma atenção particular foi dada às pesquisas sobre a Itália do Sul e insular (Sicília essencialmente), ao papel das ordens regulares na promoção dos cultos e na criação do sagrado, tanto nas grandes capitais, como Nápoles, quanto nos centros de mais reduzida dimensão urbana, sem esquecer o impacto nas áreas rurais das "índias interiores". Entre o primeiro e o segundo tomo, com efeito, o quarto percurso reúne 14 contributos consagrados ao matizado contexto do Mezzogiorno italiano, metade dos quais é dedicada a uma única província deste espaço, então sob dominação da monarquia espanhola. Aberto pelas indicações metodológicas de Elisa Novi Chavarria, que analisa alguns casos de santidade feminina napolitana entre os séculos XVI e XVII, o itinerário prossegue com Giulio Sodano, que indaga o modo através do qual os jesuítas e outras ordens regulares procuraram inserir no universo devocional dos fiéis os novos campeões da santidade, numa corte de santos caracterizados pela forte "territorialidade". Idêntica atenção à territorialização encontra-se no contributo de Marcella Campanelli, que quantifica a difusão dos cultos através da titulação das igrejas anexas aos complexos monásticos, sobre os quais predomina a mariana, nas suas distintas denominações miracolísticas o geotoponomásticas. A província do extremo sul oriental do vice-reino de Nápoles, Terra de Otranto, constituiu um observatório privilegiado para o 
estudo de Francesco Gaudioso, sobre as formas devocionais encontradas nos actos notariais relativos a testamentos de Lecce, centro político-cultural desta região, e para as pesquisas de enfoque histórico, literário e iconográfico de Katiuscia Di Rocco, Alessandro Valenti, Gino Pisanó e Lucio Galante. Também São José da Copertino (1603-1663), conventual originário da pequena comunidade da Apúlia meridional, que fora processado pela Inquisição romana por fingida santidade e depois canonizado (1767), está representado pela consistente bibliografia recolhida por Dino Levante e pelo estudo de Mario Spedicato. Baseando-se nos processos periféricos constituídos na cúria da Puglia (na diocese de Nardò) depois da morte do frade e necessários para desencadear a canonização, Spedicato não se focaliza na análise das virtutes ad admirandum como êxtases e levitações, mas antes nas heróicas qualidades do franciscano, cuja peculiaridade só pode ser lida e percebida no contexto geográfico, social e antropológico da realidade em que se integrava. Em linhas relativamente convergentes Angelo Sindoni ocupa-se dos santos padroeiros, símbolos identitários de várias comunidades sicilianas, Giuseppe Maria Viscardi consagra o seu percurso ao santo teatino originário da Basilicata, André Avellino (1521-1608), e Lina Scalisi examina as ambições territoriais do pequeno centro siciliano de Corleone, através das estratégias activadas para afirmar um modelo de santidade franciscana. Adoptando este traçado, os distintos autores apropriam-se das observações de Giuseppe Galasso em páginas ainda estimulantes para todos quantos se ocupam da "A Outra Europa" [L'altra Europa. Per un'antropologia storica del Mezzogiorno d'Italia. Milano: Mondadori, 1982; existe versão portuguesa publicada pela Bertrand em 1987]. Esta área, onde as funções taumatúrgicas são um dos aspectos da santidade melhor entendidos pelas populações autóctones como também sublinhou Maria Antonietta Rinaldi no seu estudo sobre os panegíricos dos capuchinhos, é muito bem evidenciada em confronto quer com a Itália do Norte, através do estudo de Adelisa Malena sobre a heresia quietista, quer com outras regiões europeias católicas antes da chegada da Reforma, através dos textos de Dominique de Courcelles, dedicado aos novos santos em Espanha, de Bernard Dompnier sobre as confrarias na França do século XVII, e de Heinrich Dormeier, projectado na difusão do santo padroeiro contra a nova epidemia da sífilis nas áreas aquém dos Alpes. No entanto, como notou G. Zarri, não se destrói o intento 
do projecto de identificar influências culturais e formas de organização sociais que se propagam desde a Europa mediterrânea e atlântica até os mundos ultramarinos.

Efectivamente, este fio condutor evidencia-se desde o primeiro bloco, aberto pelo estudo de R. Michetti dedicado às recolhas hagiográficas. Inserido nas grandes transformações religiosas e nas mudanças político-culturais do séculos XV-XVI, favorecido pela difusão da ars artificialiter scribendi, este afortunado género literário, se estudado sincronicamente, pode fazer compreender o papel das velhas e novas ordens empenhadas na construção, fortalecimento e invenção de uma fisionomia religiosa específica, através da exaltação dos santos próprios da ordem, em competição com as fórmulas hagiográficas propostas por outras famílias de religiosos. Um desafio entre ordens que, no exame de Robert Godding, se transforma numa avaliação numérica centralizada sobre uma excelente recolha, isto é, a Bibliotheca Sanctorum, monumental obra iniciada em 1643 por Jean Bolland. Uma numeração minuciosa das páginas e das tábuas de aparato, que se convertem num singular instrumento de medida das desigualdades e das discriminações na escrita sobre os santos. No percurso de Francesca Cantú também é visível uma multidão de religiosos: a Igreja dos frades (Iglesia de los frailes) é a protagonista do processo de aparição e de arreigamento dos santos cristãos nas sociedades do Novo Mundo. Evangelizadores e missionários das primeiras gerações, como franciscanos (chegados no fim do século XV), dominicanos, agostinianos, mercedários e por fim jesuítas (1568), todos transplantaram e veicularam crenças e cultos, segundo formas diversas, de modo não linear, nem unidireccional. Por isso, juntamente com "a galáxia das línguas" (retomando o titulo do trabalho de Maria Leonor Buescu), também uma fileira de santos da tradição cristã chegaram aos territórios do Novo Mundo. Entre eles o apóstolo São Tiago (a tradicional designação Matamoros transformou-se em Mataindios nos territórios ultramarinos) assimilado ao deus raio dos índios Yllapa, primeiro colonizador do imaginário indígena; São Tomás/Quetzacoatl, deus serpente e civilizador dos índios; e outros adaptados aos quatros elementos naturais. Ao contrário, Santa Rosa de Lima (Isabel Flores de Oliva (1586-1617)) foi a primeira santa autóctone da América, reivindicada sobretudo pelos dominicanos e franciscanos que tentaram monopolizar o seu culto. Por seu lado, também 
a monarquia hispânica, aproveitando o direito de padroado (concedido a partir do 1508), agudizou os conflitos jurisdicionais entre autoridades locais, como era o caso do clero regular e dos bispos, os quais eram, por sua vez, legitimados por poderes concorrentes, ainda que complementares: a coroa e o papado.

No fundo, F. Cantù antecipou aqui alguns aspectos tratados com mais profundidade em pesquisas posteriores [Ead. La conquista spirituale. Studi sull'evangelizzazione del Nuovo Mondo, Roma, Viella, 2007], nomeadamente a questão de saber se no culto dos santos praticado pelos ameríndios foi mascarada a sobrevivência das antigas crenças religiosas sob aparências cristãs ou então se foi representada uma forma da "colonização do imaginário" indígena através da introdução das crenças e dos ritos da religião. Do seu percurso de pesquisa resulta claro que a vinculação dos nativos do Novo Mundo à economia da santidade foi o resultado de diversas estratégias entre as quais a imposição do baptismo e por via dele dos nomes de santos sobre os referidos indígenas. Estes rituais e práticas sociais, por outro lado, também no Velho continente marcavam identidades individuais e colectivas por via de alterações e metamorfoses onomásticas, por vezes, na sequência de baptismos per vim, com consequências não indolores, retomando as propostas recentes de Adriano Prosperi [Salvezza delle anime, disciplina dei corpi. Un seminario sulla storia del battesimo, (Idem, a cura di), Pisa, Edizioni della Normale, 2006].

No percurso de afirmação social identitária e de incorporação nas comunidades, tal como na Europa católica, também na América a iconografia teve um papel decisivo, desvendando um discurso autóctone sobre a santidade, transmitido por pintores e escultores indígenas, como mostram os exemplos apresentados no contributo de F. Cantú e outros estudos que compõem o livro. O papel fulcral das imagens, favorecido no contexto tridentino da polémica anti-protestante, foi também sublinhado através das propostas metodológicas de Samuele Giombi, que se dedica a diversas formas e argumentos da predicação, e na análise de Bernadette Majorana, que focalizou o confronto, durante a primeira década do século XVIII, entre Lodovico António Muratori e Paolo Segneri junior no uso das imagens sacras como parte integrante da acção do predicador. Ponte entre a realidade do santo personagem e o público, tal como são os escritos e outros media que 
favoreceram o conhecimento e a memória daquelas extraordinárias figuras com virtudes heróicas, também sobre este produto hagiográfico recaíram os olhos da Inquisição romana. A suprema Congregação, a partir da primeira metade do século XVII, interveio legislativamente para regulamentar novos cultos, bloqueando os mais “desagradáveis". Nessa medida foi uma espécie de sismógrafo eficaz, segundo Miguel Gotor, para registar as tensões entre a autoridade central que reconhece a santidade e as ordens que promovem o processo de canonização do santo na Época Moderna, cujo perfil, a partir da legislação de Urbano VIII, ficou assim definido: masculino, filho de pais católicos, sacerdote que decidiu vestir hábito religioso e que morreu em conceito de santidade perto dos seus fiéis. Enquadrado neste padrão também o caso de S. Benedito, "o Preto" - chamado assim pela cor da pele - siciliano e filho de pais africanos e escravos, não escapou deste modelo da "demografia celeste". O padroeiro de Palermo, com efeito, muito bem conhecido no Brasil, é um santo pertencente à ordem franciscana. Aclamado santo logo depois da morte, em 1589, embora beatificado apenas em 1743 e canonizado sucessivamente em 1807, a enorme difusão do seu culto, especialmente entre os escravos, é testemunhada já em Lisboa no primeiro vinténio de Seiscentos, como também no Brasil, onde eram numerosas as confrarias que lhe eram dedicadas.

Considerações de cariz social, político, religioso e ainda étnicas encontram-se nos estudos do José Óscar Beozzo e de Giovanna Fiume. O primeiro, estendendo a pesquisa até ao século XXI, apresenta uma territorialização das devoções no Brasil, observando a toponímia das capelas e das paróquias cujo orago era S. Benedito, ou de outros espaços sacros e profanos onde o santo siciliano está colocado; G. Fiume analisa comparativamente a transmigração de S. Benedito para lugares distantes e diversos entre si como Palermo, Córdova, Madrid, Lisboa ou Recife. Em Pernambuco o seu culto enraizou_se através da actividade das confrarias que constituem um instrumento de integração nas sociedades locais, um meio de mobilidade social, assim como lugar físico e politico de orgulho identitário, agrupando os escravos pretos e mulatos. Também a rede da capilar penetração franciscana no Sul da América constituiu um extraordinário sistema para propagandear a devoção do santo preto que, mais do que outros, encarnava um modelo de santidade centrado na humildade, obediência e amor entre raças. Finalmente, ao santo 
fundador de Assis e às ordens promotoras do seu culto são dedicadas outras duas investigações esboçadas através de itinerários metodológicos não muito diversos. Sylvana Maria Brandão de Aguiar e Luiz Carlos Luz Marques ilustram a migração de São Francisco no Canidé e evidenciam o processo de inculturação na devoção ao santo que, vivendo as mesmas tribulações dos seus devotos, é mais representado como "São Francisco das Chagas" do que pelos estigmas. Por outro lado, centrado sobre a linguagem visível e sobre o uso da imagem no processo da evangelização franciscana, a análise de Isabel Cruz de Amenábar sublinha como o uso de um código expressivo menos restrito e rígido a respeito aos de outras ordens como os dominicanos, permite comunicar mensagens didácticas destinadas às conversões indígena e mestiça no vice-reino peruano, introduzindo elementos locais da paisagem, da fauna e da flora americana que veiculam profundos significados iconológicos.

De um extremo ao outro dos impérios coloniais ibéricos, movendo-se até ao Oriente, a análise de Maria Cristina Osswald evidencia a lenda do apóstolo S. Tomé no Malabar, cuja elaboração apresenta uma trama entre mitologia budista e hindu, embora os portugueses tenham sabido reformular as suas vantagens quando chegaram a Meliapor, em 1513, para justificar a sua política e a sua actividade missionária. Um dos indícios inequívocos desta forma de apropriação é a nova toponímia conferida à cidade, baptizada S. Tomé. Este centro, que custodiava os restos do santo mártir, tornou-se objecto de interesse pela coroa portuguesa, em particular dos reis D. Manuel I e D. João III, e foi utilizado em 1606 para legitimar a escolha da cidade como sede do novo bispado, depois do desmembramento de Cochim. Foram sobretudo os jesuítas, privilegiados pela coroa através da concessão da custódia do túmulo do mártir, que no Japão - mas também na Europa - difundiram o culto do S. Tomé apóstolo, aproveitando a relação privilegiada estabelecida com as autoridades locais e o sapiente uso do tráfico das inexauríveis relíquias do santo mártir. Os mesmos jesuítas são os protagonistas da investigação de Paolo Broggio que se centra sobre a pastoral missionária que desenvolveram na Espanha e no Perú do século XVII, e sobre a impossibilidade de falar em termos estritos de uma dialéctica entre centro e periferia, pela qual o centro europeu teria imposto directivas e estratégias sobre os territórios americanos periféricos. O mais correcto seria pensar num policentrismo na transmissão dos paradigmas da evangelização 
e das práticas devocionais. A ordem inaciana difundiu as devoções ligadas à figura de Cristo e da Virgem, do Santíssimo Sacramento, de Santo Estêvão. Este último foi entendido como um intermediário nas cerimónias da reconciliação, devidas à necessidade do perdão cristão, num contexto dominado pela presença de instituições seculares que reivindicavam o exclusivo monopólio do exercício da justiça. Em competição com o papel dos curandeiros e dos xamans indígenas, também o recurso ao santo fundador da ordem, se tornou "o advogado das crianças para que não morram sem o baptismo", foi favorecido pelos jesuítas, através de pequenas imagens em forma de medalha. Este patrocínio foi concretizado com a imposição do nome Inácio, escolhido ainda pelas mães como agradecimento da graça recebida. Desta maneira, combatendo o papel dos poderes religiosos locais, os missionários actuavam no complexo universo sociocultural indígena, nas ligações parentais e na desestruturação da linhagem.

$\mathrm{Na}$ conclusão desta viagem constituída por uma pluralidade de fontes escritas e figurativas de diversa tipologia e finalidade, bem como de complementares chaves metodológicas e historiográficas é inegável constatar o peso e a capacidade de acção das ordens religiosas, as quais tiveram um papel decisivo e uma ramificada presença na sociedade tanto do Novo como do Velho Mundo. Embora haja que considerar outros protagonistas e estruturas da Igreja, tais como os bispos e o clero secular, os poderes comunicativo e impositivo das ordens religiosas abateu-se sobre uma ampla área geográfica através de privilegiados e capilares instrumentos de enquadramento das populações. Expressões e modelos de referência das diversas famílias regulares, enquadradas por estratégias de controle das monarquias, também os santos e as honras a eles manifestadas fizeram parte dos delicados jogos activados para afirmar o cristianismo e um novo universo simbólico de crenças, ritos, relações e vinculações protectoras verticais e horizontais, de uma malha diversa de comportamentos e de relações. Estes poderes simbólicos, como recorda Pierre Bordieu, com tinham uma função simultaneamente estruturante e destruturante, e contribuíam para a reprodução de uma ordem social. Por isso, na tentativa de preservar a saúde das almas no corpo social, de enquadrar territorialmente e confessionalmente tanto os novos como os antigos contextos político-sociais, fixando-se nas categorias mentais profundas, também o acto de imposição de um nome de 
santo, conferido às pessoas e lugares, possuía um significado determinante: definia, delimitava e marcava as diversas fronteiras da fé e os limites sociais, jurídicos, culturais e religiosos dos espaços de conquista.

\section{Paola Nestola}

Bolseira de Pós-Doutoramento da FCT, no Centro de História da Sociedade e da Cultura paola.nestola@tin.it

CORRADINI, Pietro (dir.) - Della entrata della Compagnia di Giesù e Christianità nella Cina, com prefácio de Filippo Mignini e edição de Maddalena Del Gatto. Obra realizada pela Província de Macerata-Assessorato Beni e Attività Culturali com o contributo da Regione Marche-Assesorato da Cultura. Macerata: Quodlibet, 2000, 776 p.

No prefácio intitulado "Nel segno di Matteo Ricci”, Filippo Mignini trata do significado da vida do célebre padre jesuíta para a história das relações entre o Oriente e o Ocidente. O P. N. Trigault acrescentou cerca de 19 fólios aos 122 autógrafos do próprio Ricci, segundo a reconstrução de P. D'Elia. Foi preciso esperar três séculos, até 1911, para que o livro fosse publicado pelo P. P. Tacchi Venturi com o título Commentarij della Cina.

Sobre a vida e a obra de M. Ricci (o Li Madou), que viveu durante a dinastia chinesa Ming (1368-1644), escreve P. Corradini um texto em que aborda a importância que teve a Companhia de Jesus e Portugal nos contactos culturais, comerciais e outros com o mundo oriental. Fala do texto e das várias edições e desenvolve alguns temas de especial relevância: o alcance da obra de Ricci e a introdução da civilização europeia na China; Ricci e o conhecimento da China na Europa; Ricci perante a civilização chinesa; a visão ricciana do pensamento chinês; a sua atitude em confronto com as outras religiões; e salienta a inteligência e o tacto do ilustre filho de Macerata na aproximação que criou entre o cristianismo e as religiões da China; assim traduziu o nome de Deus por Tianzhu ("Senhor do Céu", para os convertidos, Shangdi ("Senhor do Alto") e Tian ("Céu") para os não convertidos. As controvérsias foram subindo de tom até que Roma interveio. Queria saber- 